\title{
Quantitative Imaging of Serotonergic Biosynthesis and Degradation in the Endocrine Pancreas
}

\author{
Olof Eriksson ${ }^{1}$, Ram K. Selvaraju ${ }^{1}$, Lars Johansson ${ }^{2,3}$, Jan W. Eriksson ${ }^{3,4}$, Anders Sundin ${ }^{5}$, Gunnar Antoni², \\ Jens Sörensen ${ }^{2}$, Barbro Eriksson ${ }^{4}$, and Olle Korsgren ${ }^{6}$ \\ ${ }^{I}$ Department of Medicinal Chemistry, Preclinical PET Platform, Uppsala University, Uppsala, Sweden; ${ }^{2}$ Department of Radiology, \\ Oncology and Radiation Sciences, Uppsala University, Uppsala, Sweden; ${ }^{3}$ AstraZeneca R\&D, Mölndal, Sweden; ${ }^{4}$ Department of \\ Medical Sciences, Uppsala University, Uppsala, Sweden; ${ }^{5}$ Department of Radiology, Karolinska University Hospital, Stockholm, \\ Sweden; and ${ }^{6}$ Department of Immunology, Genetics and Pathology, Uppsala University, Uppsala, Sweden
}

Serotonergic biosynthesis in the endocrine pancreas, of which the islets of Langerhans is the major constituent, has been implicated in insulin release and $\beta$ cell proliferation. In this study, we investigated the feasibility of quantitative noninvasive imaging of the serotonergic metabolism in the pancreas using the PET tracer ${ }^{11} \mathrm{C}-5$-hydroxy-Ltryptophan $\left({ }^{11} \mathrm{C}-5-\mathrm{HTP}\right)$. Methods: Uptake of ${ }^{11} \mathrm{C}-5-\mathrm{HTP}$, and its specificity for key enzymes in the serotonergic metabolic pathway, was assessed in vitro (INS-1 and PANC1 cells and human islet and exocrine preparations) and in vivo (nonhuman primates and healthy and diabetic rats). Results: In vitro tracer uptake in endocrine cells (INS-1 and human islets), but not PANC1 and exocrine cells, was mediated specifically by intracellular conversion into serotonin. Pancreatic uptake of ${ }^{11} \mathrm{C}-5-\mathrm{HTP}$ in nonhuman primates was markedly decreased by inhibition of the enzyme dopa decarboxylase, which converts ${ }^{11} \mathrm{C}-5-$ $\mathrm{HTP}$ to ${ }^{11} \mathrm{C}$-serotonin and increased after inhibition of monoamine oxidase-A, the main enzyme responsible for serotonin degradation. Uptake in the rat pancreas was similarly modulated by inhibition of monoamine oxidase- $\mathrm{A}$ and was reduced in animals with induced diabetes. Conclusion: The PET tracer ${ }^{11} \mathrm{C}-5-\mathrm{HTP}$ can be used for quantitative imaging of the serotonergic system in the endocrine pancreas.

Key Words: 5-hydroxy tryptophan; serotonin biosynthesis; beta cell imaging; diabetes

J Nucl Med 2014; 55:460-465

DOI: 10.2967/jnumed.113.125187

$\mathbf{T}$ he endocrine cell population accounts for only a small part of the pancreas but is of paramount importance for the human metabolism. The islets of Langerhans are the major constituent of the neuroendocrine pancreas, and neuronal tissue makes up the remaining part. Several neurotransmitter systems present in the central nervous system, such as the dopaminergic and serotonergic systems, are expressed also in the islets of Langerhans $(1,2)$, and serotonin in particular has been implicated in insulin secretion $(3,4)$ and $\beta$ cell proliferation during pregnancy $(5)$. Because the exocrine pancreas is devoid of these systems, we proposed that

\footnotetext{
Received Apr. 19, 2013; revision accepted Oct. 28, 2013.

For correspondence or reprints contact: Olof Eriksson, Preclinical PET Platform (PPP), Department of Medicinal Chemistry, Uppsala University, Box 574, SE-751 23 Uppsala, Sweden.

E-mail: olof.eriksson@pet.medchem.uu.se

Published online Feb. 13, 2014.

COPYRIGHT (c) 2014 by the Society of Nuclear Medicine and Molecular Imaging, Inc.
}

quantitative noninvasive imaging of the endocrine pancreas is feasible.

The PET ligand 5-hydroxy-L- ${ }^{11} \mathrm{C}$-tryptophan $\left({ }^{11} \mathrm{C}-5-\mathrm{HTP}\right)$ is the biogenic precursor for serotonin and was originally developed to assess the rate of serotonin biosynthesis by dopa decarboxylase (DDC) in the central nervous system (6). After intracellular conversion into ${ }^{11} \mathrm{C}$-serotonin and uptake into secretory vesicles by vesicular monoamine transporter 2 or biodegradation by monoamine oxidase $\mathrm{A}$ (MAO-A) into ${ }^{11} \mathrm{C}$-5-hydroxyindoleacetic acid $\left({ }^{11} \mathrm{C}-\mathrm{HIAA}\right)$, the tracer is rapidly excreted into the urine. ${ }^{11} \mathrm{C}-5-$ HTP is currently in clinical use for localization of neuroendocrine tumors (NETs) $(7,8)$ because of the high uptake in these lesions due to the proposed amine precursor uptake and decarboxylase mechanism. Uptake of ${ }^{11} \mathrm{C}-5-\mathrm{HTP}$ in the normal human pancreas is generally high, but this has not previously been systematically investigated despite the fact that islets and some neuronal tissue constitute the only amine precursor uptake and decarboxylase tissue within the pancreas. Ekholm et al. investigated the fate of tritiated 5-HTP in the rodent pancreas and at 60 min after administration found preferential accumulation in islets of Langerhans and, in particular, in the granules of the $\beta$ cells (9). Recently, Di Gialleonardo et al. studied the mechanisms of ${ }^{11} \mathrm{C}-5$-HTP uptake in cell lines derived from rodent insulinoma (INS-1) and human ductal cells (PANC1) and reported DDC- and MAO-Aspecific uptake in INS-1 but not in PANC1 cells (10). However, the total uptake and retention in PANC1 was in the same range as for INS-1, potentially causing a significant background signal from nonendocrine tissue in vivo. In particular, the authors suggest that inhibition of MAO-A-mediated degradation of ${ }^{11} \mathrm{C}$-serotonin may improve the endocrine-specific signal, compared with background. Clearly, the fate of ${ }^{11} \mathrm{C}-5$-HTP in the pancreas merits further investigation to resolve these conflicting results in rodents.

Here, we investigated whether ${ }^{11} \mathrm{C}-5$-HTP can indeed be used for quantitative imaging of serotonergic biosynthesis and MAOA-mediated degradation in the endocrine pancreas in the nonhuman primate. Second, we studied the feasibility of using ${ }^{11} \mathrm{C}-5-\mathrm{HTP}$ as an imaging surrogate marker for islets of Langerhans by examining the correlation between ${ }^{11} \mathrm{C}-5$-HTP uptake and the development of diabetes.

\section{MATERIALS AND METHODS \\ Staining Procedures \\ Human pancreatic biopsies, embedded in paraffin wax, were sec- tioned into $4-\mu \mathrm{m}$ slices and incubated with antiserotonin antibody (AHP522HT; AbD Serotec) as primary. The stains were developed}


by the Envision DAB system K4010 (DAKO) using an antirabbit secondary antibody. All sections were counterstained using Mayer hematoxylin. The slides were captured digitally at $1.6 \times$ magnification using a camera-mounted Leica DMLB2 microscope (Leica Microsystems GmbH).

\section{In Vitro ${ }^{11} \mathrm{C}-5-\mathrm{HTP}$ Uptake in Human Islets, INS-1, and PANC1 Cells}

Human islets were acquired through the Nordic Network for Clinical Islet Transplantation. The islets were isolated as described previously (11). Islet preparations from 4 different donors with varying islet purities (7\%-90\%) were incubated with $0.5-1.0 \mathrm{MBq}$ of ${ }^{11} \mathrm{C}-5-\mathrm{HTP}$ in $1 \mathrm{~mL}$ of CMRL-1066 (pH 7.4; Cellgro) for $30 \mathrm{~min}$ at $37^{\circ} \mathrm{C}$ either alone or together with $10 \mu \mathrm{M}$ carbidopa (Karbidopa; Apoteket $\mathrm{AB}$ ). INS-1 or PANC1 cells were incubated with $0.5-1.0 \mathrm{MBq}$ of ${ }^{11} \mathrm{C}-5-\mathrm{HTP}$ in $1 \mathrm{~mL}$ of phosphate-buffered saline for 15,30 , or $60 \mathrm{~min}$ at $37^{\circ} \mathrm{C}$ either alone or together with $10 \mu \mathrm{M}$ carbidopa, $50 \mu \mathrm{M}$ 5-HTP, or $50 \mu \mathrm{M}$ clorgyline. All samples were repeated in triplicate. ${ }^{11} \mathrm{C}-5-$ HTP was produced according to standardized procedures (6).

After incubation, tissue samples (islets, INS-1 or PANC1 cells) were filtered with washing buffer Tris- $\mathrm{HCl}(50 \mathrm{mM}, \mathrm{pH}$ 7.4) through Whatman GF/C filter paper (pore size, $1.2 \mu \mathrm{m}$; Semat International Ltd.), using a cell harvester (Brandel). The radioactivity in the cells trapped on the filter was measured in a $\mathrm{NaI}(\mathrm{Tl})$ well counter (Uppsala Imanet $\mathrm{AB}$ ) and was corrected for radioactive decay. Data were analyzed using GraphPad Prism 5 (GraphPad).

For the islet experiments, the correlation between tracer uptake and preparation purity in each batch was determined by linear regression. As comparisons between different islet isolation preparations can be difficult because of, for example, differences in metabolic state, variable ischemia time, or donor status, we corrected for this by a normalization procedure. First, we estimated the expected uptake in a fraction of $100 \%$ pure islets by applying a linear regression curve to the uptake data from each individual batch. Tracer uptake in all fractions with different purities within each isolation batch was normalized to this value, giving each a value between 0 and 1, to allow for direct comparison between batches. Preparations with the same purities in different batches were collated together, giving 7 data points in total.

\section{Nonhuman Primate Imaging}

The nonhuman primate experiments were performed in accordance with the guidelines of the Uppsala University and were approved by the local ethics committee for animal research (C160/11). Cynomolgus monkeys ( $n=7,5300-8900 \mathrm{~g})$ were sedated by intravenous ketamin $(10 \mathrm{mg} / \mathrm{kg})$ and propofol before being intubated and connected to a respirator. After intubation, the animal was maintained on $1.4 \%-4 \%$ sevoflurane inhalation anesthesia and artificial ventilation. Body temperature, heart rate, electrocardiogram, $\mathrm{pCO}_{2}, \mathrm{pO}_{2}, \mathrm{SaO}_{2}$, and blood pressure were monitored throughout the study. Two venous catheters were applied, 1 for tracer and drug administration and 1 for blood sampling and measurements of radioactivity.

The animal was positioned to include the abdomen in the $15-\mathrm{cm}$ axial field of view of a Discovery ST PET/CT scanner (GE Healthcare) by assistance of a low-dose CT scout view (140 kV, $10 \mathrm{mAs})$. Attenuation correction was acquired by a $140-\mathrm{kV}$, Auto mA $10-80$ $\mathrm{mA} \mathrm{CT}$ examination. For all examinations, ${ }^{11} \mathrm{C}-5-\mathrm{HTP}(5-20 \mathrm{MBq} / \mathrm{kg})$ was administered intravenously, and the animal was examined by a dynamic PET protocol for 90 min (33 frames; $12 \times 10,6 \times 30,5 \times$ $120,5 \times 300$, and $5 \times 600 \mathrm{~s}$ ). At $3-5 \mathrm{~h}$ before the ${ }^{11} \mathrm{C}-5$-HTP examination, 3 of the animals were administered intravenously with carbidopa $(3 \mathrm{mg} / \mathrm{kg}$ ) dissolved in $0.9 \% \mathrm{NaCl}$, to investigate the effect on tissue kinetics by inhibiting DDC. At $0.5 \mathrm{~h}$ before the ${ }^{11} \mathrm{C}-5$-HTP examination, 3 of the animals were administered intravenously with clorgyline $(2 \mathrm{mg} / \mathrm{kg})$ dissolved in $0.9 \% \mathrm{NaCl}$, to investigate to effect on tissue kinetics by inhibiting MAO-A.
Venous blood samples $(0.2 \mathrm{~mL})$ were collected at $0.5,1,3,5,10$, $15,20,30,45,60$, and $90 \mathrm{~min}$ after each injection to measure the radioactivity concentration in whole blood and in plasma. For 4 animals (examined as baseline $[n=4]$ or after preadministration of carbidopa $[n=1]$ or clorgyline $[n=3]$ ), we performed analysis of tracer metabolites to investigate effect on ${ }^{11} \mathrm{C}-5$-HTP metabolism by inhibition of DDC and MAO-A. Blood samples (1.5-2.5 mL) were drawn at 5,30, and $60 \mathrm{~min}$ after tracer administration for analysis of tracer metabolites in plasma.

Tracer Metabolite Analysis of ${ }^{11} \mathrm{C}-5$-HTP. Each blood sample was centrifuged at 4,000 rpm for $2 \mathrm{~min}$ at $4^{\circ} \mathrm{C}$ (Beckman Allegra X-22R Centrifuge). One milliliter of plasma was taken, and $1.0 \mathrm{~mL}$ of $7 \% \mathrm{w} / \mathrm{v}$ perchloric acid was added to precipitate the proteins. The mixture was centrifuged at $13,200 \mathrm{rpm}$ at $4^{\circ} \mathrm{C}$ for 1 min (Eppendorf 5415R centrifuge; Eppendorf AG). The supernatant was filtered through a $0.2-\mu \mathrm{m}$ nylon membrane (Corning Inc.) by centrifugation at $13,200 \mathrm{rpm}$ at $4{ }^{\circ} \mathrm{C}$ for $1 \mathrm{~min}$. Ten microliters of unlabeled HTP $(1 \mathrm{mg} / \mathrm{mL})$, HIAA, and serotonin (5-HT) were added to the supernatant. The sample preparation recovery was determined by measuring the radioactivity in the plasma, filters, and pellet.

Image Analysis. Image acquisition was performed in 3 dimensions and reconstructed using an iterative ordered-subset expectation maximization VUEPOINT (GE Healthcare) algorithm ( 2 iterations/21subsets, in a $128 \times$ 128 matrix; zoom, 50-cm diameter). Reconstructed data were analyzed by PMOD (PMOD Technologies Ltd.). Regions of interest were delineated on coregistered transaxial CT slices. Entire organs were delineated on sequential slices and combined into volumes of interest.

\section{Small-Animal Studies}

Sprague-Dawley and Lewis rats (age, 6-8 wk; weight, 250-350 g) were housed under standard laboratory conditions with free access to food and water. All handling and experiments were performed in accordance with the guidelines of the Uppsala University and were approved by the local ethics committee for animal research (C215/09, C49/10).

Induction of Diabetes. Diabetes was induced by a single intravenous injection of streptozotocin (STZ; 50-60 mg/kg of body weight) (SigmaAldrich) dissolved in $0.9 \% \mathrm{NaCl}$. Body weight and blood glucose levels in these diabetic animals were monitored, and diabetes was defined as sequential measurements of greater than $15 \mathrm{mM}$ blood glucose.

Ex Vivo Organ Distribution. Healthy $(n=16)$ or diabetic (STZ, 50$60 \mathrm{mg} / \mathrm{kg}, n=12$ ) rats under general isoflurane anesthesia $(3.6 \%)$ were administered ${ }^{11} \mathrm{C}-5$-HTP intravenously into the tail. A subgroup of the controls $(n=4)$ was preadministered glucose $(0.3 \mathrm{mg} / \mathrm{kg})$ $10 \mathrm{~min}$ before tracer injection to induce acute hyperglycemia. Subgroups of both the control $(n=4)$ and the diabetic $(n=4)$ groups were preadministered clorgyline $(2 \mathrm{mg} / \mathrm{kg}) 10 \mathrm{~min}$ before tracer injection to inhibit MAO-A-mediated degradation. The animals were allowed to wake up after tracer administration and were sacrificed by $\mathrm{CO}_{2} 30$ or 60 min after injection. Tissues of interest were immediately excised, and the radioactivity concentrations were measured in a $\mathrm{NaI}$ (Tl) well counter and related to the administered amount of tracer and the animal weight by standardized uptake values (SUVs) to allow for comparison between animals. The organ uptake data were analyzed using GraphPad Prism 5. The pancreases were frozen to $-80^{\circ} \mathrm{C}$ and later thawed in cold acetone and fixed in paraffin wax. Five consecutive $4-\mu \mathrm{m}$ slices from each pancreas were stained for insulin using A0564 from DAKO as the primary antibody. The stains were developed by the Envision DAB system K4010 (DAKO) using an antirabbit secondary antibody. All slices were counterstained using Mayer hematoxylin. The slides were captured digitally at $1.6 \times$ magnification using a cameramounted Leica DMLB2 microscope (Leica Microsystems GmbH). The images were analyzed with ImageJ (National Institutes of Health) using thresholding to delineate the total tissue area, whereas the insulinstained areas were delineated manually. The diabetic rats were further 


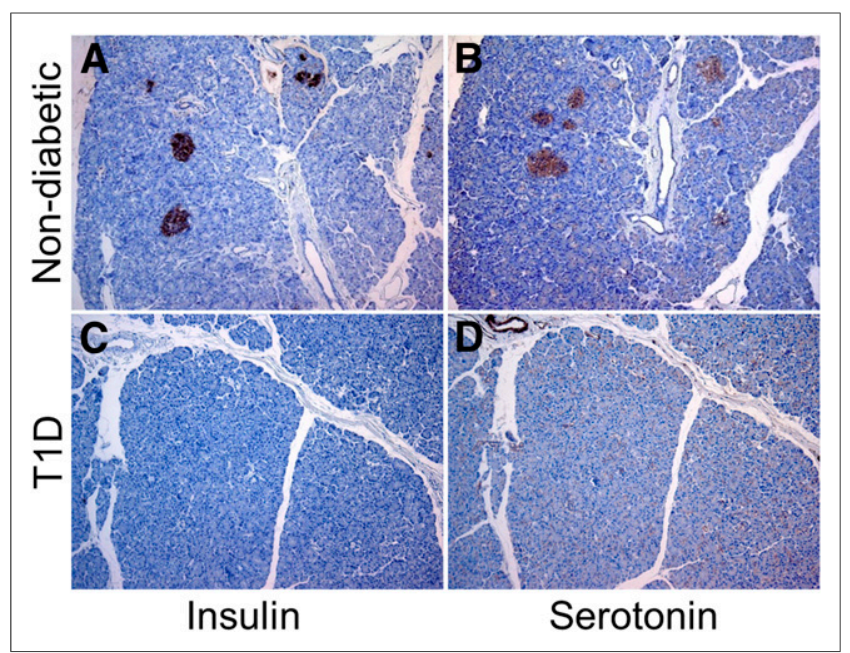

FIGURE 1. Immunohistochemical staining on serial sections of human pancreas was performed for insulin ( $A$ and $C$ ) and serotonin (B and $D)$. Serotonin is localized in islets of Langerhans in nondiabetic subject ( $A$ and $B$ ) but not in islets of subject with longstanding T1D (C and D). Disappearance of serotonin is correlated with loss of insulin but not with glucagon.

divided into 2 groups, depending on their remaining relative $\beta$ cell area (BCA), using the average of all measured percentages in the diabetic group as the cutoff point. The HTP uptake was reported both individually and at the group level.

Small-Animal Imaging. Healthy $(n=4)$ or STZ-treated $(50 \mathrm{mg} / \mathrm{kg}$, $n=3)$ rats were sedated by isoflurane, controlled by an anesthesia vaporizer (3.0\% isoflurane) blended with $450 \mathrm{~mL} / \mathrm{min}$ air/ $\mathrm{O}_{2}$ delivered through a face mask. The animal was placed on the heated bed of a Triumph Trimodality system (Gamma Medica Inc.) to prevent hypothermia. The breathing rate and body temperature were monitored by an integrated physiologic monitoring system. ${ }^{11} \mathrm{C}-5$-HTP in a maximum volume of $500 \mu \mathrm{L}$ was administered as single bolus injection via a tail vein catheter, and the animal underwent small-animal PET examination of the abdomen for $60 \mathrm{~min}$ in list mode. The datasets were reconstructed into 8 time frames $(4 \times 5$ and $4 \times 10 \mathrm{~min})$ using a maximum-likelihood expectation maximization 3-dimensional algorithm (10 iterations). Small-animal PET data were analyzed using PMOD (version 3.13; PMOD Technologies Ltd.). Volumes of interest were drawn manually to include the pancreas, liver, and other tissues of interest in early or summed frames, and the uptake was expressed as SUV. After PET imaging, tissues of interest were immediately excised,
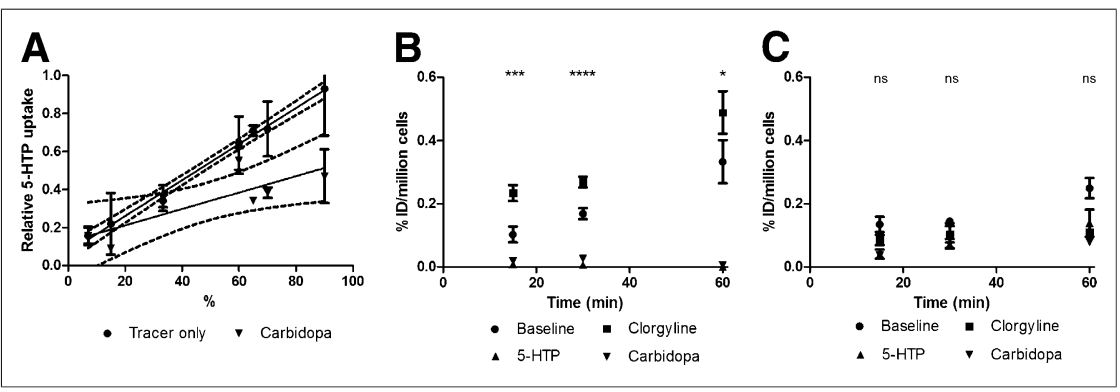

FIGURE 2. (A) There is a strong linear correlation $\left(R^{2}=0.99, P<0.05\right)$ between islet purity and ${ }^{11} \mathrm{C}-5$-HTP uptake in human islet preparations $(n=4)$. Extrapolation predicts low uptake in exocrine tissue and at least 15 -fold increased uptake in islets. ${ }^{11} \mathrm{C}-5$-HTP uptake was partially inhibited by coincubation with DDC inhibitor carbidopa, confirming biosynthesis of ${ }^{11} \mathrm{C}$-serotonin in islets in vitro. ${ }^{11} \mathrm{C}-5-\mathrm{HTP}$ uptake in INS-1 cells (B), but not PANC1 (C), could be modulated by inhibition of DDC and MAO-A (stars indicate significance between clorgyline treatment, compared with baseline) or competition by unlabeled 5-HTP in excess. and the radioactivity concentrations were measured in a $\mathrm{NaI}(\mathrm{Tl})$ well counter and related to the administered amount of tracer and the animal weight by SUV.

\section{Statistics}

Results on group levels are reported as mean \pm SEM unless otherwise stated. The area under the curve (AUC) was analyzed by GraphPad Prism 5. A 2-tailed Student $t$ test (cell studies) or a nonparametric Mann-Whitney test (animal studies) was used to test for significance. In Figures 2-4, an asterisk (*) denotes $P<0.05 ; 2$ asterisks (**), $P<$ $0.01 ; 3$ asterisks $(* * *), P<0.001$; and 4 asterisks $(* * * *), P<0.0001$.

\section{RESULTS}

\section{In Vitro Studies of Serotoninergic System in Human Pancreas}

Initially, we performed immunohistochemical staining of human pancreatic biopsies retrieved from pancreases procured from organ donors to avoid autolysis. Specimens were obtained from patients with longstanding type 1 diabetes (T1D) or from subjects with no history of pancreatic disorder. Serotonin was localized primarily in the islets of Langerhans (Fig. 1), that is, both $\alpha$ and $\beta$ cells, with almost no expression in any other pancreatic tissue. Within the islets of nondiabetic subjects, almost all cells expressed serotonin (Figs. 1A and 1B). However, in patients with T1D, the expression of serotonin was markedly decreased in islets devoid of insulin (Figs. 1C and 1D) but still with a distinct expression of glucagon (data not shown). We concluded that the expression of serotonin in the diabetic pancreas is markedly deceased when compared with that observed in nondiabetic subjects.

In vitro cell labeling of isolated human islets mixed with exocrine tissue in different ratios demonstrated a linear correlation between ${ }^{11} \mathrm{C}-5$-HTP uptake and the fraction of islets (Fig. 2A). Part of the cellular uptake could be inhibited by carbidopa. Linear regression analysis estimated the in vitro uptake in pure islet samples to be at least 14 times higher than in the exocrine cells.

The accumulation of ${ }^{11} \mathrm{C}-5$-HTP in INS-1 cells was linear with respect to time of incubation for up to $60 \mathrm{~min}$, and the uptake was increased by inhibiting MAO-A or abolished by competition by unlabeled 5-HTP in excess or inhibition of DDC (Fig. 2B). The uptake in PANC1 cells was not mediated by conversion into ${ }^{11} \mathrm{C}-5$ HT because it was neither inhibited by coincubation with carbidopa or 5-HTP nor increased by inhibition of MAO-A (Fig. 2C).

\section{${ }^{11} \mathrm{C}-5-\mathrm{HTP}$ Imaging in Nonhuman Primates}

Time-dependent accumulation of ${ }^{11} \mathrm{C}-5$ HTP in the pancreas in nondiabetic nonhuman primates expressed as SUV is shown in Figure 3. Pancreatic uptake reached a peak at 5-10 min, followed by washout of radioactive metabolites into the urine (Figs. 3A and $3 \mathrm{C}$ ). Pancreatic uptake of ${ }^{11} \mathrm{C}-5$-HTP was markedly decreased when administrated together with carbidopa (Figs. 3A and 3D). Inhibition was most pronounced during the initial peak; however, the difference remained during the washout phase (Fig. 3B, baseline AUC $=406.3 \pm 79.3$; carbidopa pretreatment group $\mathrm{AUC}=173.4 \pm 56.5, P<0.05)$. The uptake of ${ }^{11} \mathrm{C}-5$-HTP in the liver, on the other hand, was increased (Supplemental Fig. 1A; supplemental materials are available at http://jnm.snmjournals.org) because 


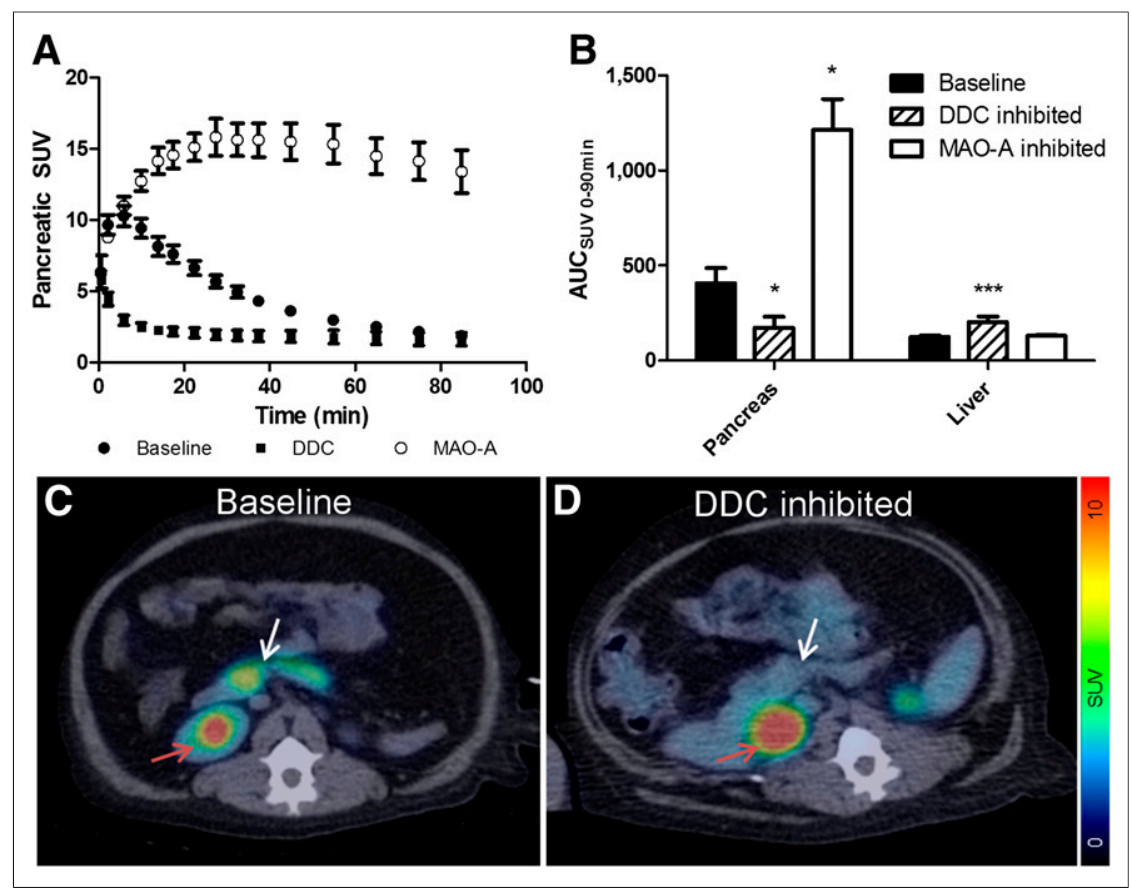

FIGURE 3. PET measurements of ${ }^{11} \mathrm{C}-5-\mathrm{HTP}$ uptake in pancreas $(\mathrm{A})$ of nonhuman primate are plotted over time. $\bullet={ }^{11} \mathrm{C}-5$-HTP uptake in pancreas; $\boldsymbol{\square}={ }^{11} \mathrm{C}-5$-HTP uptake when administered together with carbidopa; and $\circ={ }^{11} \mathrm{C}-5$-HTP uptake when administered together with clorgyline. ${ }^{11} \mathrm{C}-5-\mathrm{HTP}$ uptake in pancreas (as measured by AUC) was significantly decreased by intravenous preadministration of DDC inhibitor carbidopa or increased by intravenous preadministration of MAO-A-inhibitor clorgyline (B). Enhancement in hepatic uptake after administration of carbidopa (B) when compared with tracer alone is explained by increase in circulating amounts of ${ }^{11} \mathrm{C}-5$-HTP when administered together with carbidopa when compared with injection of tracer alone. (C and D) Abdominal HTP and PET/CT fusion images of nonhuman primate. Tracer uptake in pancreas (white arrow) is distinct $(C)$, whereas no uptake is seen in nonendocrine organs such as spleen. Urinary excretion of tracer metabolites causes intense uptake in kidney pelvis (red arrow). Distinct pancreatic uptake is almost completely abolished by pretreatment by carbidopa (D).

inhibition of DDC by carbidopa increases the amount of native tracer available for tissue distribution in plasma (Supplemental Fig. 1B; Fig. 3B, baseline AUC $=124.8 \pm 7.2$ and carbidopa pretreatment group AUC $=202.0 \pm 30.5, P<0.05)$.

Inhibition of MAO-A, on the other hand, markedly increased the retention of ${ }^{11} \mathrm{C}-5$-HTP in the pancreas (Fig. 3A), reaching SUVs in excess of 15 (baseline AUC $=406.3 \pm 79.3$; clorgyline pretreatment group AUC $=1,214 \pm 161.7, P<0.05)$. Plasma ${ }^{11} \mathrm{C}-5-\mathrm{HTP}$
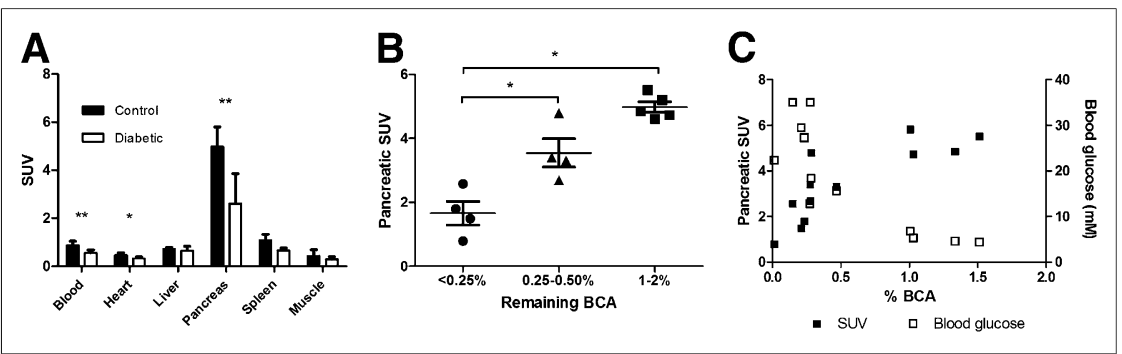

FIGURE 4. Organ distribution after administration of ${ }^{11} \mathrm{C}-5-\mathrm{HTP}$ shows distinct uptake in pancreas, whereas tissues devoid of serotonergic enzymatic systems required for tracer metabolism (such as heart, liver, and muscle) show low accumulation $30 \mathrm{~min}$ after tracer administration (A). In diabetic animals, ${ }^{11} \mathrm{C}-5$-HTP uptake in pancreas is reduced $30 \mathrm{~min}$ after administration (A and B). Treatment with STZ induced progressive hyperglycemia through selective destruction of pancreatic $\beta$ cells (C). In vivo ${ }^{11} \mathrm{C}-5-\mathrm{HTP}$ uptake in pancreas is significantly decreased in diabetic, compared with nondiabetic, rats and correlated with remaining relative BCA, as assessed by morphometric analysis (B and $C$ ).
(Supplemental Fig. 1B) and hepatic uptake of tracer (Supplemental Fig. 1A) were not affected by clorgyline (Fig. 3B, baseline $\mathrm{AUC}=124.8 \pm 7.2$ and clorgyline pretreatment group AUC $=130.8 .2 \pm 5.4$ ).

${ }^{11} \mathrm{C}-5-H T P$ Imaging in Small Animals:
Healthy Individuals and Models of T1D

${ }^{11} \mathrm{C}-5$-HTP uptake after intravenous injection in rats showed a distinct pancreatic uptake of the tracer, with a peak at 5$10 \mathrm{~min}$, followed by washout of radioactive metabolites such as ${ }^{11} \mathrm{C}$-5-HIAA into urine (Supplemental Fig. 2A). These findings show clear similarities with those obtained in nonhuman primate. The AUC was decreased in diabetic animals (control group AUC $[\mathrm{SUV}>1]=133.6 \pm 12.6$; diabetic group AUC [SUV $>1]=78.9 \pm$ 14.0, $P<0.05)$. Organ distribution studies showed a marked accumulation in the pancreas of nondiabetic rats, whereas no accumulation of the tracer was found in the blood, heart, liver, or muscle (Fig. 4A). Uptake in the pancreas, blood, and heart was decreased by induction of diabetes by STZ. Next, we performed an intravenous glucose tolerance test (IVGTT) in nondiabetic rats to examine whether extensive insulin secretion would influence tracer accumulation in the islets. ${ }^{11} \mathrm{C}-5-\mathrm{HTP}$ was administered either before the infusion of glucose or at the peak of blood glucose concentration $(>15 \mathrm{mmol} / \mathrm{L})$. The ambient blood glucose level and insulin secretion had no effect (control group SUV $=4.98 \pm 0.34$; IVGTT group $\mathrm{SUV}=5.06 \pm 0.67, P=1.0$ ) on the pancreatic uptake of ${ }^{11} \mathrm{C}-5-\mathrm{HTP}$. Intravenous administration of $50-60 \mathrm{mg} / \mathrm{kg}$ of body weight of the $\beta$-cell toxin STZ caused loss of insulin-positive cells, resulting in hyperglycemia after $2-4 \mathrm{~d}$. The remaining BCA was determined after immunohistochemical staining for insulin and digital morphometric analysis. BCA was expressed as percentage of total pancreatic area. Control rats had a BCA between $1 \%$ and $2 \%$, with a mean of $1.29 \% \pm 0.26 \%$. The diabetic group was stratified into 2 groups, rats with either intermediate remaining BCA $(0.25 \%-0.50 \%$, with a mean of $0.32 \% \pm$ $0.09 \%)(50 \mathrm{mg} / \mathrm{kg} \mathrm{STZ}, n=3 ; 55 \mathrm{mg} / \mathrm{kg}$ STZ, $n=1)$ or severe loss of BCA $(<0.25 \%$, with a mean of $0.15 \% \pm 0.1 \%)(55 \mathrm{mg} / \mathrm{kg}$ STZ, $n=3 ; 60 \mathrm{mg} / \mathrm{kg} \mathrm{STZ,} n=1)$. The pancreatic uptake of ${ }^{11} \mathrm{C}$-5-HTP in the STZtreated group with severe loss of BCA was significantly decreased, compared with the control group $(\mathrm{SUV}=4.98 \pm 0.34, P<$ $0.05)$ as measured by organ distribution 30 min after administration (Fig. 4B). In addition, the diabetic group with the lowest insulin-positive area had reduced tracer uptake, compared with the group with less severe $\beta$ cell loss $(\mathrm{SUV}=3.55 \pm 0.44$ vs. 
SUV $=1.66 \pm 0.75, P<0.05)$. The pancreatic uptake of ${ }^{11} \mathrm{C}-5$ HTP in the most diabetic animals was decreased to SUVs below 1 (Fig. 4C).

The inhibition of MAO-A by clorgyline increased the accumulation of ${ }^{11} \mathrm{C}-5$-HTP in healthy rats by up to 3 -fold (Supplemental Fig. $2 \mathrm{~B}, P<0.05$ ). A similar increase (4-fold, $P<0.05$ ) was seen in diabetic rats. The decrease of tracer accumulation in the pancreas in diabetic rats, compared with healthy rats (on average $48 \%$ decrease), was actually lower after MAO-A inhibition (32\% decrease).

\section{DISCUSSION}

Here, we present evidence that ${ }^{11} \mathrm{C}-5$-HTP can be used for quantitative imaging of the serotonergic system in the endocrine pancreas. Furthermore, we find indications that serotonergic metabolism, as measured by ${ }^{11} \mathrm{C}-5$-HTP PET, is related to development of diabetes or the remaining insulin positive islet mass.

Preadministration of carbidopa before ${ }^{11} \mathrm{C}-5$-HTP is an established procedure in clinical PET/CT of NETs (12). Carbidopa, an inhibitor of the enzyme DDC (13), delays the conversion of ${ }^{11} \mathrm{C}-5$ HTP to ${ }^{11} \mathrm{C}-5$-hydroxy-tryptamin $\left({ }^{11} \mathrm{C}-5-\mathrm{HT}\right.$, that is, serotonin). Consequently, the plasma concentration of the tracer increases, thereby allowing higher tracer uptake in NETs, in which availability of the tracer, rather than DDC, is the limiting factor. However, the use of carbidopa seems counterintuitive in studies aiming to quantify serotonergic facilitation in tissues such as the $\beta$ cells within the islets of Langerhans. Indeed, in nonhuman primates, carbidopa markedly decreased ${ }^{11} \mathrm{C}-5$-HTP uptake in the pancreas and we concluded that the established clinical procedure with preadministration of carbidopa is not optimal for studies of serotonergic metabolism in nonmalignant tissues such as the endocrine pancreas. In contrast, the inhibition of MAO-A by clorgyline markedly increased the retention of ${ }^{11} \mathrm{C}-5-\mathrm{HTP}$ in the nonhuman primate pancreas, illustrating a rapid turnover of serotonin in the neuroendocrine pancreas.

Ekholm et al. found that ${ }^{3} \mathrm{H}-5-\mathrm{HTP}$ accumulated in islets of Langerhans as opposed to the exocrine pancreatic parenchyma in mice. Furthermore, the uptake was similar in magnitude in $\alpha$ and $\beta$ cells, but the retention in $\beta$ cells was higher, resulting in an increased relative accumulation in $\beta$ cells 60 min after intravenous administration with $75 \%$ of the tracer found within the $\beta$ cells (9). Di Gialleonardo et al. (10) performed in vitro uptake studies using the ductal cell line PANC1 as a model for exocrine tissue. They showed that accumulation in PANC1 cells was comparable to that of INS-1 cells but not mediated by normal serotonergic metabolism because the accumulated tracer metabolite was resistant to degradation by MAO-A. They concluded that the endocrine signal potentially would drown in the exocrine nonspecific signal and further suggested that inhibition of MAO-A could improve the endocrineto-exocrine signal ratio. Here, we demonstrate that inhibition of MAO-A by clorgyline markedly increases the pancreatic uptake in healthy rats (as previously shown) and to a lesser degree in diabetic rats. In fact, the uptake ratio between diabetic and healthy animals was not increased by pretreatment by clorgyline, even though the absolute difference was amplified. Again, the findings of Ekholm et al. (9) explain this paradox because they showed that the major effect on ${ }^{3} \mathrm{H}-5$-HTP cellular uptake by MAO-A inhibition is an increased retention in $\alpha$ cells. We concluded that MAO-A inhibition may assist in understanding the serotonergic metabolism in the pancreas, but the procedure does not increase the contrast between $\beta$ cells and other pancreatic (endocrine or exocrine) tissues.
Furthermore, we show that almost the entire ${ }^{11} \mathrm{C}-5-\mathrm{HTP}$ uptake in the pancreas in nonhuman primate is mediated specifically by DDC and thus consists of ${ }^{11} \mathrm{C}$-serotonin or its metabolites. Thus, the findings by Di Gialleonardo et al. (10) in the PANC1 cell line may not be representative for higher species such as nonhuman primates or humans.

The possibilities of quantitative imaging of the endocrine pancreas carry obvious consequences in regards to visualizing its major constituent, the pancreatic $\beta$ cell. We therefore investigated the effect on serotonin biosynthesis by ${ }^{11} \mathrm{C}-5-\mathrm{HTP}$ imposed by the diabetic condition in rats. We found a decrease over all time points, compared with healthy animals. When correlating between the pancreatic uptake (as assessed by organ distributions studies $30 \mathrm{~min}$ after tracer administration) and the $\beta$ cell-positive area, the correlation was parabolic rather than linear. The preadministration of carbidopa or unlabeled 5-HTP in rodents (data not shown) elicited a response to ${ }^{11} \mathrm{C}-5$-HTP uptake similar to that seen in NET patients (i.e., the uptake is increased due to markedly increased native ${ }^{11} \mathrm{C}-5$-HTP in the circulation). This does not mean that the high ${ }^{11} \mathrm{C}-5$-HTP uptake in rodent endocrine pancreas or human NETs is nonspecific, but it entails that we cannot easily inhibit the uptake by competition.

In the context of imaging in diabetes, ${ }^{11} \mathrm{C}-5$-HTP is a marker for both $\alpha$ and $\beta$ cells (but with 4 times higher retention in $\beta$ cells) (9). This is in contrast to previously reported radiotracers based on analogs of the glucagon like peptide-1 (GLP-1), which targets the GLP-1 receptor (GLP-1R) (14). GLP-1R is present on the $\beta$ cells but not on other endocrine cells within the islets (15). However, immunoreactivity for GLP-1R has also been found in pancreatic ducts in humans (15), which potentially may generate a significant pancreatic signal from ${ }^{68} \mathrm{Ga}$-DO3A-Exendin 4 also in subjects with negligible $\beta$ cell mass. Recent published communications raise questions concerning the $\beta$ cell specificity of the GLP-1R probe, in which the total integrated uptake in the pancreas, not adjusted for differences in pancreatic volumes, of subjects with manifest T1D was reduced only by approximately $55 \%$ of the signal in healthy volunteers (16).

Dysfunction or loss of $\beta$ cells is a hallmark of both T1D and type 2 diabetes, but the viability of other islet cells is obviously also important for glucose homeostasis. It is therefore speculated that a 2-dimensinal PET approach, for example, sequential ${ }^{11} \mathrm{C}-5-$ HTP and ${ }^{68} \mathrm{Ga}$-DO3A-Exendin4 scanning in the same subject, may give significant complementary data in the evaluation of the human endocrine pancreas during the progress or treatment of diabetes. Dual measurements of serotonin biosynthesis and GLP-1R expression in the pancreas would be analogous to, for example, sequential Pittsburgh compound B (PIB)/ ${ }^{18} \mathrm{~F}-\mathrm{FDG}$ scanning of amyloid burden and glucose metabolism, respectively, in the brain of subjects with suspected Alzheimer disease (17).

${ }^{11} \mathrm{C}-5$-HTP intracellular metabolism includes several enzymatic steps, and quantification of each of these by compartmental modeling may therefore appear complex. Previously, both a 1-tissueand a 2-tissue-compartmental model have been used to assess the serotonin biosynthesis step (DDC) in the primate pancreas and the brain $(6,18)$. These relatively simple models can reasonably describe the pharmacokinetics of ${ }^{11} \mathrm{C}-5$-HTP when administered alone. However, not surprisingly these models are not complex enough to describe DDC and MAO-A activity when pretreating by either carbidopa or clorgyline. We are currently developing a population-based pharmacometric model that includes 3 serial tissue compartments including irreversible transport from plasma 
to compartment 1 (DDC activity), elimination from compartment 2 (MAO-A activity), and irreversible transport from compartment 2 to compartment 3 (vesicular monoamine transporter 2 activity).

\section{CONCLUSION}

The PET tracer ${ }^{11} \mathrm{C}-5-\mathrm{HTP}$ can be used for quantitative imaging of the serotonergic system in the endocrine pancreas and is potentially a tool for future noninvasive imaging of the endocrine pancreas.

\section{DISCLOSURE}

The costs of publication of this article were defrayed in part by the payment of page charges. Therefore, and solely to indicate this fact, this article is hereby marked "advertisement" in accordance with 18 USC section 1734. This study was supported by grants from the Swedish Medical Research Council (65X-12219-15-6), the VINNOVA foundation (2007-00069), JDRF, Tore Nilssons Foundation, and Barndiabetesfonden. Additional support was provided by EXODIAB (Excellence of Diabetes Research in Sweden) and the National Institutes of Health (2U01AI065192-06). Human pancreatic islets were obtained from The Nordic Network for Clinical Islet Transplantation, supported by the Swedish national strategic research initiative EXODIAB and JDRF. Lars Johansson and Jan W Eriksson are employees of AstraZeneca R\&D. No other potential conflict of interest relevant to this article was reported.

\section{ACKNOWLEDGMENTS}

We thank Veronika Asplund (Preclinical PET Platform, department of Medicinal Chemistry, Uppsala University) for technical assistance.

\section{REFERENCES}

1. Maffei A, Liu Z, Witkowski P, et al. Identification of tissue-restricted transcripts in human islets. Endocrinology. 2004;145:4513-4521.

2. Simpson NR, Souza F, Witkowski P, et al. Visualizing pancreatic beta-cell mass with $\left[{ }^{11}\right.$ C]DTBZ. Nucl Med Biol. 2006;33:855-864.
3. Paulmann N, Grohmann M, Voigt JP. at al. Intracellular serotonin modulates insulin secretion from pancreatic beta-cells by protein serotonylation. PLOS Biol. 2009; 7:e1000229.

4. Ohta Y, Kosaka Y, Kishimoto N, et al. Convergence of the insulin and serotonin programs in the pancreatic beta-cell. Diabetes. 2011;60:3208-3216.

5. Kim H, Toyofuku Y, Lynn FC, et al. Serotonin regulates pancreatic beta cell mass during pregnancy. Nat Med. 2010;16:804-808.

6. Lundquist P, Blomquist G, Hartvig P, et al. Validation studies on the 5-hydroxyL-[beta- ${ }^{11} \mathrm{C}$-tryptophan/PET method for probing the decarboxylase step in serotonin synthesis. Synapse. 2006;59:521-531.

7. Orlefors H, Sundin A, Ahlstrom H, et al. Positron emission tomography with 5-hydroxytryprophan in neuroendocrine tumors. J Clin Oncol. 1998;16:25342541.

8. Orlefors H, Sundin A, Garske U, et al. Whole-body ${ }^{11} \mathrm{C}-5$-hydroxytryptophan positron emission tomography as a universal imaging technique for neuroendocrine tumors: comparison with somatostatin receptor scintigraphy and computed tomography. J Clin Endocrinol Metab. 2005;90:3392-3400.

9. Ekholm R, Ericson LE, Lundquist I. Monoamines in the pancreatic islets of the mouse: subcellular localization of 5-hydroxytryptamine by electron microscopic autoradiography. Diabetologia. 1971;7:339-348.

10. Di Gialleonardo V, Signore A, Scheerstra EA, et al. ${ }^{11} \mathrm{C}$-hydroxytryptophan uptake and metabolism in endocrine and exocrine pancreas. J Nucl Med. 2012;53:17551763.

11. Goto M, Eich TM, Felldin M, et al. Refinement of the automated method for human islet isolation and presentation of a closed system for in vitro islet culture. Transplantation. 2004;78:1367-1375.

12. Orlefors $\mathrm{H}$, Sundin A, Lu L, et al. Carbidopa pretreatment improves image interpretation and visualisation of carcinoid tumours with ${ }^{11} \mathrm{C}$-5-hydroxytryptophan positron emission tomography. Eur J Nucl Med Mol Imaging. 2006;33:60-65.

13. Daidone F, Montioli R, Paiardini A, et al. Identification by virtual screening and in vitro testing of human DOPA decarboxylase inhibitors. PLOS ONE. 2012; 7:e31610.

14. Selvaraju RK, Velikyan I, Johansson L, et al. In vivo imaging of the glucagonlike peptide 1 receptor in the pancreas with ${ }^{68} \mathrm{Ga}$-labeled DO3A-exendin-4. J Nucl Med. 2013;54:1458-1463.

15. Tornehave D, Kristensen P, Rømer J, et al. Expression of the GLP-1 receptor in mouse, rat, and human pancreas. J Histochem Cytochem. 2008;56:841-851.

16. Van der Weg W, Brom M, Janssen MJR, et al. ${ }^{111}$ In-exendin for non-invasive quantification of beta cell mass in patients with type 1 diabetes and healthy controls [abstract]. Diabetologia. 2013;56(suppl):5080.

17. Nordberg A, Rinne JO, Kadir A, et al. The use of PET in Alzheimer disease. Nat Rev Neurol. 2010;6:78-87.

18. Eriksson O, Selvaraju RK, Borg B, et al. 5-fluoro- $\left[\beta-{ }^{11} \mathrm{C}\right]$-L-tryptophan is a functional analogue of 5-hydroxy-[ $\left.\beta-{ }^{11} \mathrm{C}\right]$-L-tryptophan in vitro but not in vivo. Nucl Med Biol. 2013;40:567-575. 